\title{
Investigation of the dielectric properties of copolymers based on 2,3,4,5,6-pentafluorostyrene, styrene, 4-fluoro- $\alpha$-methylstyrene and $\alpha$-methylstyrene
}

\author{
(C) Ignat S. Dolgin, Pyotr P. Purygin, ${ }^{*}$ and Yury P. Zarubin ${ }^{+}$ \\ Department of Inorganic Chemistry. Samara National Research University. \\ Moskovskoe Ave., 34. Samara, 443086. Samara Region. Russia. \\ Phone: +7 (846) 334-54-59. E-mail: puryginpp2002@mail.ru
}

\begin{abstract}
*Supervising author; ${ }^{+}$Corresponding author Keywords: macromolecular compounds, styrene, fluorine-containing copolymers, dielectric, permittivity, dielectric loss tangent.
\end{abstract}

\begin{abstract}
Three new copolymers based on fluorine-containing derivatives of styrene and $\alpha$-methylstyrene were obtained. According to the results of the previous stages of the study, copolymers based on styrene derivatives have improved dielectric properties compared to polystyrene and a copolymer of styrene and $\alpha$-methyl styrene. The dielectric constant $\varepsilon$ and dielectric loss tangent $\tan \delta$ were measured for the initial and synthesized samples of styrene - $\alpha$-methyl styrene copolymer at Samara Electromechanical Plant OJ-SC (Samara city, Russia). All measurements of dielectric characteristics were carried out at an alternating current frequency of $10 \mathrm{GHz}$ on a pressed copolymer tablet with a diameter of 10 and a thickness of $3 \mathrm{~mm}$. During the experiment, a measuring stand was used, consisting of a high-frequency signal generator G4-83, an electronically counting frequency meter Ch3-54 with a frequency converter YaZCh-43, a measuring amplifier U2-4; low-frequency signal generator G3-109; measuring unit FKDG 418151.002. The results obtained indicate high values of the dielectric constant. For samples of copolymers of $\alpha$-methylstyrene - 4-fluoro- $\alpha$-methylstyrene and styrene - 4fluoro- $\alpha$-methylstyrene, values of 4.63 and 4.21, respectively, were obtained. These dielectric permittivity values are superior not only to samples previously obtained during the experiment, but also to some other compounds that are widely used in industry. In particular, the dielectric constant of lavsan, which is used in the manufacture of capacitors, is 3.1-3.3. The improved dielectric constant values are probably related to the high-quality composition of the copolymer. Samples of the copolymer containing 4-fluoro- $\alpha$-methylstyrene are significantly superior to the copolymer with 2,3,4,5,6-pentafluorostyrene for this characteristic. The values of the dielectric loss tangent are in the range from $8.74 \cdot 10^{-4}$ to $37.4 \cdot 10^{-4}$. Given the dielectric characteristics of the synthesized copolymers, we can conclude that there are good prospects for the use of fluorine-containing styrene copolymers. The obtained values of permittivity and dielectric loss tangent indicate a good possible competitiveness of new materials based on new copolymers. In the future, it is planned to study a number of other physicochemical properties of these materials in order to obtain the most complete spectrum of their characteristics.
\end{abstract}

\section{References}

[1] I.S. Dolgin, Yu.P. Zarubin, and P.P. Purygin. Investigation of the dielectric properties of styrene- $\alpha-$ methylstyrene copolymer obtained with various anionic and non-ionic emulsifiers. Butlerov Communications. 2017. Vol.52. No.11. P.144-146. DOI: 10.37952/ROI-jbc-01/17-52-11-144

[2] I.S. Dolgin, P.P. Purygin, and Yu.P. Zarubin. Study of dielectric properties of 4-methylstyrene and $\alpha-$ methylstyrene copolymer films with different molar ratio of initial monomers. Butlerov Communications. 2019. Vol.58. No.6. P.55-58. DOI: $10.37952 /$ ROI-jbc-01/19-58-6-55

[3] V.K. Kryzhanovsky, V.V. Burlov, A.D. Panimatchenko, Yu.V. Kryzhanovskaya. Technical properties of polymeric materials. 2nd ed. SPb .: Profession. 2005. 248p. 